\title{
FORMULATION AND EVALUATION OF ZOLPIDEM TARTRATE LAYERED TABLETS BY MELT GRANULATION TECHNIQUE FOR TREATMENT OF INSOMNIA
}

\author{
RAMYA SRI A, LATHA K* \\ Department of Pharmaceutics, G. Pulla Reddy College of Pharmacy, Mehdipatnam - 500 028, Hyderabad, India. \\ Email: lathakukatil@gmail.com
}

Received: 25 July 2017, Revised and Accepted: 21 February 2018

\begin{abstract}
Objective: The main objective of this study was to formulate and evaluate the sustained release matrix tablets of zolpidem tartrate, using hydrogenated vegetable oil as a polymer.

Methods: Various formulations were prepared by melt granulation method using concentrations Lubritab, HPMC K100, and lactose monohydrate. The optimized formulations were prepared as three-layered tablets using HPMC K4M.

Results: All formulations blend were evaluated for various precompression parameters were found to be good. The drug and excipients compatibility study was performed, and the study revealed that there was no interaction between drug and excipients. The compressed tablets were evaluated for various physicochemical parameters. The initial release from the matrix tablet was higher which was reduced by the preparation of three-layered tablet using HPMC K4M. The initial release was controlled to 10-12\%, but the complete release was not there in $12 \mathrm{~h}$. To get the complete release of the drug pore forming agent such as lactose and HPMC K100 was included in the matrix. ZT22 and ZT25 were considered as optimized formulations, and the drug release at $12^{\text {th }} \mathrm{h}$ is $98.85 \%$ and $98.3 \%$ respectively. The optimized formulation was subjected to stability studies for 3 months as per ICH guidelines for climate zone III and was found to be stable.
\end{abstract}

Conclusion: Difficulties with sleep onset and or sleep maintenance can be treated successfully using the optimized formulations ZT22 and ZT25 for the prompt onset of action of the drug over a prolonged period of time which may lead to improved efficacy, better patient compliance.

Keywords: Matrix tablets, Sustained release formulations, Layered tablets, Melt granulation technique.

(C) 2018 The Authors. Published by Innovare Academic Sciences Pvt Ltd. This is an open access article under the CC BY license (http://creativecommons. org/licenses/by/4. 0/) DOI: http://dx.doi.org/10.22159/ajpcr.2018.v11i6.21540

\section{INTRODUCTION}

Oral drug delivery is the most preferred method of administering the drugs for the systemic effects. In addition, the oral medication is, generally, considered as the first choice for investigated new drugs in the discovery and development of pharmaceutical formulations because of patient compliance, convenience in administration and economic manufacturing process [1].

Oral drug delivery systems can be classified into immediate release and modified release systems. Immediate release dosage forms are designed to release the drug immediately or at least as quickly as possible after administration. This is useful if a fast onset of action is required for therapeutic reasons. However, they have some disadvantages such as increased frequency of administration and fluctuations in drug plasma levels [2]. To overcome these disadvantages the modified release systems have been developed. Modified release dosage forms are designed to extend the release of the drug over a period of time or after the dosage form reaches the required site.

Oral modified release delivery systems are most commonly used for (1) delayed-release using an enteric coating, which are formulated to release the drug with a time lag not immediately after administration. (2) Extended-release (e.g. zero-order, first-order, and biphasic release) where the drug to be released over prolonged period of time. It can be achieved using sustained or controlled release dosage forms. (3) Programmed release such as pulsatile and triggered aims to release drugs on a predetermined pattern and (4) site-specific or timed release (e.g. for colonic delivery or gastric retention and chronotherapeutic drug delivery system) [3]. These systems release the drug to a specific site and/or time.
The present study aims to formulate and evaluate sustained release three-layered tablets of zolpidem tartrate, a BCS Class I drug with short half-life for treatment of insomnia, using a combination of hydrophobic and hydrophilic polymers [4]. The goal of the study is the development of matrix tablets using Lubritab and layered with the hydrophilic polymer to prolong the duration of action thereby reduces the frequency of administration and improves the patient compliance. Slow and extended-release is advisable for treatment of insomnia.

\section{METHODS}

Zolpidem tartrate, Lubritab are gift samples from Microlabs, Bengaluru, HPMC K100, HPMC K4M, AVICEL PH 102 purchased from Yarrow chem. Products.

\section{Preformulation studies}

Preformulation testing is the foremost primitive step in the rational development of dosage forms by investigation of physical and chemical properties of a drug alone and combination with excipients.

\section{Preparation of blend of drug and excipients}

All the ingredients were subjected to grinding to a required degree of fineness and passed through sieve no 60 then powder blend was subjected to precompression parameters.

\section{Angle of repose}

This is the maximum angle formed between the pile of powder and horizontal plane. The frictional forces which are equal to the coefficient friction $(\mu)$ between the particles in loose powder can be measured 
by angle of repose. Hence, the rough and more irregular surfaces of particles form the greater angle of repose.

\section{Procedure}

About $100 \mathrm{~g}$ of the blend was weighed and poured through the funnel whose tip was fixed at the height of $2.5 \mathrm{~cm}$ above the graph paper which is placed on a horizontal surface. The blend was poured till the apex of the pile touches the tip of the funnel. Angle of repose is then calculated by the following formula.

$\theta=\operatorname{Tan}^{-1}(\mathrm{~h} / \mathrm{r})$

Where, $\theta=$ angle of repose, $r=$ radius of the pile, $h=$ height of the pile.

\section{Bulk density}

Bulk density is defined as a mass of a powder divided by the bulk volume.

\section{Procedure}

Parent bulk density $\left({ }^{*} \mathrm{~b}\right)$ was determined by pouring the blend into a graduated cylinder. The bulk volume $\left(\mathrm{V}^{*}\right)$ and weight of the powder (M) were determined. The bulk density was calculated using the formula.

$* \mathrm{~b}=\mathrm{M} / \mathrm{V}^{*}$

\section{Tapped density}

The measuring cylinder containing a known mass of blend was tapped for a fixed time (around 250). The minimum volume ( $\mathrm{V}_{\mathrm{t}}$ ) occupied in the cylinder and the weight $(\mathrm{M})$ of the blend was measured. The tapped density $\left({ }^{*} \mathrm{t}\right)$ was calculated using the formula.

${ }^{*} \mathrm{t}=\mathrm{M} / \mathrm{V}_{\mathrm{t}}$

\section{Compressibility index (C.I)}

The free flow of powder is measured by compressibility, an indication of the ease with which a material can be induced to flow is given by C.I which is calculated using the formula.

$$
\text { C.I (\%) }=\frac{\text { Tapped density }- \text { Bulkdensity }}{\text { Tappeddensity }} \times 100
$$

\section{Hausner's ratio}

Hausner's ratio is an indirect index of the free flow of powder. It was calculated by the using the formula:

Hausner ratio $=* \mathrm{t} / * \mathrm{~d}$

Where, *t=tapped density. ${ }^{*} \mathrm{~d}=$ bulk density

\section{Preparation of tablets by direct compression (DC)}

In DC drug and polymer were mixed thoroughly in geometrical proportions, and then the remaining ingredients were added and compressed at maximum compression force with $6 \mathrm{~mm}$ flat round punch.

\section{Preparation of tablets by melt granulation (MG)}

In MG granules were prepared by melting Lubritab at a constant temperature of $55-60^{\circ} \mathrm{C}$. Drug and diluents were gradually added to the molten mass with continuous stirring. The molten mixture was then allowed to cool and solidify at room temperature and pulverized in a mortar and passed through a sieve No. 16 for dry screening. Magnesium stearate and talc were added and compressed at maximum compression force with $6 \mathrm{~mm}$ flat round punch [5-8]

Tablets were prepared using the drug to polymer ratios from 1:1 to $1: 6$ by MG technique as given in Table 1. Preparations ZT7-ZT9 were given in Table 2 containing the drug to polymer ratio 1:0.5 and 1:1 are formulated. Formulations ZT8 and ZT9 were layered top and bottom using a hydrophilic polymer. Initially, the core tablet was slightly precompressed and was layered top and bottom with HPMC K4M [9-11]. Tablets were prepared with different diluents and channeling agents (HPMC K100 and lactose monohydrate at concentrations of $2.5 \%, 5 \%$, and $10 \%$ ) (Table 3). Tablets were

Table 1: Formulations with different concentrations of polymer

\begin{tabular}{llllllll}
\hline $\begin{array}{l}\text { Ingredients } \\
(\mathbf{m g})\end{array}$ & \multicolumn{7}{l}{ Formulations } \\
\cline { 2 - 8 } & ZT1 & ZT2 & ZT3 & ZT4 & ZT5 & ZT6 & ZT7 \\
\hline $\begin{array}{l}\text { Zolpidem } \\
\text { tartrate }\end{array}$ & 6.25 & 6.25 & 6.25 & 6.25 & 6.25 & 6.25 & 6.25 \\
$\begin{array}{l}\text { Lubritab } \\
\text { AVICEL }\end{array}$ & 3.125 & 6.25 & 12.5 & 18.75 & 25 & 31.25 & 37.5 \\
$\begin{array}{l}\text { PH 102 } \\
\begin{array}{l}\text { Magnesium } \\
\text { stearate }\end{array}\end{array}$ & 0.5 & 0.5 & 0.5 & 0.5 & 0.5 & 0.5 & 0.5 \\
$\begin{array}{l}\text { Talc } \\
\text { Total }\end{array}$ & 1 & 1 & 1 & 1 & 1 & 1 & 1 \\
weight (mg) & 50 & 50 & 50 & 50 & 50 & 50 & 50 \\
\hline
\end{tabular}

Table 2: Formulations for optimization of polymer concentration

\begin{tabular}{llll}
\hline \multirow{2}{*}{ Ingredients (mg) } & \multicolumn{2}{l}{ Formulations } \\
\cline { 2 - 4 } & ZT7 & ZT8 & ZT9 \\
\hline Zolpidem tartrate & 6.25 & 6.25 & 6.25 \\
Lubritab & 3.125 & 6.25 & 6.25 \\
AVICEL PH 102 & 39.125 & 36 & 36 \\
Magnesium stearate & 0.5 & 0.5 & 0.5 \\
Talc & 1 & 1 & 1 \\
HPMC K4M (upper CR layer) & - & 12.5 & 25 \\
HPMC K4M (lower CR layer) & - & 12.5 & 25 \\
Total weight (mg) & 50 & 75 & 100 \\
\hline
\end{tabular}

Table 3: Formulations with channeling agents

\begin{tabular}{lllllll}
\hline \multirow{2}{*}{ Ingredients (mg) } & \multicolumn{7}{l}{ Formulations } & & & \\
\cline { 2 - 7 } & ZT10 & ZT11 & ZT12 & ZT13 & ZT14 & ZT15 \\
\hline Zolpidem tartrate & 6.25 & 6.25 & 6.25 & 6.25 & 6.25 & 6.25 \\
Lubritab & 12.5 & 12.5 & 12.5 & 12.5 & 12.5 & 12.5 \\
HPMC K100 & 1.25 & 2.5 & 5 & - & - & - \\
Lactose & - & - & - & 1.25 & 2.5 & 5 \\
monohydrate & & & & & & \\
AVICEL PH 102 & 28.5 & 27.25 & 24.75 & 28.5 & 27.25 & 24.75 \\
Magnesium & 0.5 & 0.5 & 0.5 & 0.5 & 0.5 & 0.5 \\
stearate & & & & & & \\
Talc & 1 & 1 & 1 & 1 & 1 & 1 \\
Total weight (mg) & 50 & 50 & 50 & 50 & 50 & 50 \\
\hline
\end{tabular}

Table 4: Formulations layered with HPMC K4M

\begin{tabular}{lllll}
\hline \multirow{2}{*}{ Ingredients (mg) } & \multicolumn{2}{l}{ Formulations } & \\
\cline { 2 - 5 } & ZT16 & ZT17 & ZT18 & ZT19 \\
\hline Zolpidem tartrate & 6.25 & 6.25 & 6.25 & 6.25 \\
Lubritab & 12.5 & 12.5 & 12.5 & 12.5 \\
HPMC K100 & 5 & - & - & - \\
Lactose monohydrate & - & 1.25 & 2.5 & 5 \\
AVICEL PH 102 & 24.75 & 28.5 & 27.25 & 24.75 \\
Magnesium stearate & 0.5 & 0.5 & 0.5 & 0.5 \\
Talc & 1 & 1 & 1 & 1 \\
HPMC K4M (upper layer) & 12.5 & 12.5 & 12.5 & 12.5 \\
HPMC K4M (lower layer) & 12.5 & 12.5 & 12.5 & 12.5 \\
Total weight (mg) & 75 & 75 & 75 & 75 \\
\hline
\end{tabular}


prepared using the channeling agent at different concentrations (10\% HPMC K100 and 2.5, and 5 and 10\% lactose monohydrate) as given in Table 4 and subsequent formulations were prepared with different concentrations of channeling agents and HPMC K4M layers $(15 \%, 20 \%$, and $22.5 \%$ HPMC K100 and 5\%, 10\%, and $12.5 \%$ lactose monohydrate) as given in Table 5. To optimize dissolution media for complete drug release in $12 \mathrm{~h}$ the dissolution was performed in both 7.4 and $6.8 \mathrm{pH}$ buffers.

\section{Evaluation of sustained release matrix tablets}

The prepared tablets are evaluated for various parameters such as weight variation, thickness, hardness, friability, drug content, content uniformity, and in vitro dissolution studies [12].

\section{Weight variation}

Twenty tablets were randomly selected, and average weight was determined. Then, individual tablets were weighed, and percent deviation from the average was calculated. Percentage deviation allowed for the tablets is given in Table 7.

Table 5: Formulations for optimization of channeling agents in layered tablets

\begin{tabular}{lllllll}
\hline Ingredients (mg) & \multicolumn{7}{c}{ Formulations } & & & \\
\cline { 2 - 7 } & ZT20 & ZT21 & ZT22 & ZT23 & ZT24 & ZT25 \\
\hline Zolpidem tartrate & 6.25 & 6.25 & 6.25 & 6.25 & 6.25 & 6.25 \\
Lubritab & 12.5 & 12.5 & 12.5 & 12.5 & 12.5 & 12.5 \\
HPMC K100 & 7.5 & 10 & 11.25 & - & - & - \\
Lactose & - & - & - & 2.5 & 5 & 6.25 \\
monohydrate & & & & & & \\
AVICEL PH 102 & 22.25 & 19.75 & 18.5 & 27.25 & 24.75 & 23.5 \\
Magnesium & 0.5 & 0.5 & 0.5 & 0.5 & 0.5 & 0.5 \\
stearate & 1 & 1 & 1 & 1 & 1 & 1 \\
$\begin{array}{l}\text { Talc } \\
\text { HPMC }\end{array}$ & 12.5 & 12.5 & 12.5 & 25 & 25 & 25 \\
$\begin{array}{l}\text { K4M (upper layer) } \\
\text { HPMC K4M }\end{array}$ & 12.5 & 12.5 & 12.5 & 25 & 25 & 25 \\
(lower layer) & & & & & & \\
Total weight (mg) & 75 & 75 & 75 & 100 & 100 & 100 \\
\hline
\end{tabular}

Thickness

Physical dimensions of the tablets such as size and thickness are essential for acceptance and tablet-tablet uniformity. The diameter of tablets depends on the size of die and punches. The thickness of tablet-related to the hardness and is measured by screw gauge. Tablet thickness should be controlled within the range of $\pm 5 \%$ variation of standard value. The thickness in millimeters $(\mathrm{mm})$ was measured individually for 10 pre-weighed tablets using screw gauge. The average thickness and standard deviation were reported.

\section{Hardness}

The strength of tablet is expressed as tensile strength $\left(\mathrm{Kg} / \mathrm{cm}^{2}\right)$. The tablet crushing load is the force required to break a tablet into pieces by compression. It is measured using a tablet hardness tester (Monsanto hardness tester). Five tablets from each formulation batch were tested randomly, and the average reading noted.

\section{Friability}

Friability of the tablets is determined using Roche Friabilator (Electrolab, India). It consists of a plastic chamber which revolves at a speed of $25 \mathrm{rpm}$ for $4 \mathrm{~min}$ and dropping the tablets at a distance of 6 inches for each revolution. A preweighed sample of tablets were placed in the friabilator and subjected for 100 revolutions. Tablets were dusted using a soft muslin cloth and reweighed. The friability (F\%) is given by the formula

$\mathrm{F} \%=\left(1-\mathrm{W}_{0} / \mathrm{W}\right) \times 100$

Where, $\mathrm{W}_{0}$ is weight of the tablets before the test and $\mathrm{W}$ is the wt of the tablets after test.

\section{Drug content}

Twenty tablets were randomly selected and were powdered in a glass mortar. Powder equivalent to $12.5 \mathrm{mg}$ was weighed and dissolved in $100 \mathrm{ml}$ of $0.01 \mathrm{~N} \mathrm{HCl}$, filtered and analyzed by UV spectrophotometer at $294.4 \mathrm{~nm}$.

\section{Content uniformity}

The content uniformity test is used to ensure that each tablet contains the amount of drug substance intended with little variation among

Table 6: Precompression parameters of the powder blend of all formulations

\begin{tabular}{|c|c|c|c|c|c|}
\hline Formula tion & Angle of repose $(\theta)^{*}$ & Bulk density $\left(\mathrm{g} / \mathrm{cm}^{3}\right)^{*}$ & Tapped density $\left(\mathrm{g} / \mathrm{cm}^{3}\right)^{*}$ & Hausner's ratio* & C.I $(\%)^{*}$ \\
\hline ZT1 & $25.26 \pm 1.03$ & $0.642 \pm 0.014$ & $0.735 \pm 0.004$ & $1.144 \pm 0.019$ & $12.58 \pm 1.520$ \\
\hline ZT2 & $25.12 \pm 0.98$ & $0.646 \pm 0.006$ & $0.735 \pm 0.009$ & $1.137 \pm 0.003$ & $12.09 \pm 0.233$ \\
\hline ZT3 & $25.78 \pm 0.82$ & $0.617 \pm 0.004$ & $0.722 \pm 0.003$ & $1.170 \pm 0.013$ & $14.53 \pm 0.926$ \\
\hline ZT4 & $26.89 \pm 0.80$ & $0.634 \pm 0.005$ & $0.720 \pm 0.008$ & $1.136 \pm 0.022$ & $11.99 \pm 1.739$ \\
\hline ZT5 & $27.21 \pm 0.72$ & $0.645 \pm 0.005$ & $0.742 \pm 0.005$ & $1.150 \pm 0.001$ & $13.24 \pm 0.169$ \\
\hline ZT6 & $25.62 \pm 0.53$ & $0.652 \pm 0.012$ & $0.740 \pm 0.003$ & $1.134 \pm 0.021$ & $11.89 \pm 0.562$ \\
\hline ZT7 & $27.89 \pm 0.92$ & $0.669 \pm 0.024$ & $0.757 \pm 0.002$ & $1.131 \pm 0.019$ & $11.62 \pm 0.327$ \\
\hline ZT9 & $26.97 \pm 0.86$ & $0.630 \pm 0.005$ & $0.710 \pm 0.006$ & $1.126 \pm 0.019$ & $11.24 \pm 1.491$ \\
\hline ZT10 & $27.78 \pm 0.78$ & $0.642 \pm 0.007$ & $0.712 \pm 0.009$ & $1.128 \pm 0.007$ & $11.82 \pm 0.070$ \\
\hline ZT11 & $26.58 \pm 0.94$ & $0.654 \pm 0.011$ & $0.728 \pm 0.003$ & $1.130 \pm 0.009$ & $12.16 \pm 1.202$ \\
\hline ZT12 & $26.62 \pm 0.90$ & $0.658 \pm 0.003$ & $0.749 \pm 0.002$ & $1.138 \pm 0.002$ & $12.20 \pm 0.127$ \\
\hline ZT13 & $27.26 \pm 0.69$ & $0.669 \pm 0.002$ & $0.788 \pm 0.006$ & $1.127 \pm 0.002$ & $11.29 \pm 0.324$ \\
\hline ZT13 & $27.26 \pm 0.69$ & $0.669 \pm 0.002$ & $0.788 \pm 0.006$ & $1.127 \pm 0.002$ & $11.29 \pm 0.324$ \\
\hline ZT14 & $27.76 \pm 0.76$ & $0.610 \pm 0.013$ & $0.692 \pm 0.005$ & $1.134 \pm 0.009$ & $11.84 \pm 0.141$ \\
\hline ZT15 & $26.32 \pm 0.69$ & $0.660 \pm 0.010$ & $0.750 \pm 0.011$ & $1.135 \pm 0.001$ & $11.93 \pm 0.084$ \\
\hline ZT17 & $26.26 \pm 1.01$ & $0.644 \pm 0.006$ & $0.732 \pm 0.013$ & $1.137 \pm 0.011$ & $12.06 \pm 0.841$ \\
\hline ZT18 & $26.34 \pm 0.82$ & $0.661 \pm 0.008$ & $0.746 \pm 0.012$ & $1.128 \pm 0.010$ & $11.39 \pm 0.782$ \\
\hline ZT19 & $26.26 \pm 0.69$ & $0.668 \pm 0.010$ & $0.758 \pm 0.016$ & $1.134 \pm 0.006$ & $11.87 \pm 0.816$ \\
\hline ZT20 & $27.54 \pm 0.81$ & $0.646 \pm 0.005$ & $0.728 \pm 0.003$ & $1.126 \pm 0.004$ & $11.19 \pm 0.339$ \\
\hline ZT21 & $25.21 \pm 0.68$ & $0.615 \pm 0.005$ & $0.694 \pm 0.006$ & $1.129 \pm 0.018$ & $11.44 \pm 1.435$ \\
\hline ZT22 & $26.78 \pm 1.03$ & $0.670 \pm 0.002$ & $0.755 \pm 0.003$ & $1.126 \pm 0.011$ & $11.25 \pm 1.332$ \\
\hline ZT23 & $27.78 \pm 0.78$ & $0.642 \pm 0.012$ & $0.740 \pm 0.003$ & $1.130 \pm 0.009$ & $11.19 \pm 0.562$ \\
\hline ZT24 & $27.65 \pm 0.53$ & $0.659 \pm 0.024$ & $0.727 \pm 0.002$ & $1.138 \pm 0.002$ & $11.32 \pm 0.327$ \\
\hline ZT25 & $26.12 \pm 1.03$ & $0.641 \pm 0.004$ & $0.752 \pm 0.002$ & $1.127 \pm 0.002$ & $11.58 \pm 0.332$ \\
\hline
\end{tabular}


Table 7: Evaluation of the prepared zolpidem tartrate layered tablets

\begin{tabular}{|c|c|c|c|c|c|c|}
\hline Formulation & $\begin{array}{l}\text { Weight } \\
\text { variation }^{\mathrm{a}}(\mathrm{mg})\end{array}$ & $\operatorname{Hardness}^{\mathrm{b}}\left(\mathrm{Kg} / \mathrm{cm}^{2}\right)$ & Friability $^{\mathrm{c}}(\%)$ & Thickness $^{\mathrm{d}}(\mathrm{mm})$ & Drug content ${ }^{\circ}$ & Content uniformity ${ }^{f}$ \\
\hline ZT1 & $51 \pm 0.82$ & $7-8$ & $0.1 \pm 0.15$ & $2.63 \pm 0.12$ & $98.07 \pm 0.02$ & $98.43 \pm 0.12$ \\
\hline ZT2 & $51 \pm 0.78$ & $7-8$ & $0.105 \pm 0.34$ & $2.61 \pm 0.54$ & $98.43 \pm 0.007$ & $97.36 \pm 0.57$ \\
\hline ZT3 & $49 \pm 0.12$ & $7-8$ & $0.12 \pm 0.15$ & $2.61 \pm 0.31$ & $97.71 \pm 0.008$ & $98.17 \pm 0.84$ \\
\hline ZT4 & $50 \pm 0.53$ & $7-8$ & $0.109 \pm 0.34$ & $2.62 \pm 0.31$ & $99.08 \pm 0.28$ & $97.84 \pm 0.16$ \\
\hline ZT5 & $51 \pm 0.26$ & $7-8$ & $0.107 \pm 0.24$ & $2.61 \pm 0.84$ & $98.15 \pm 0.31$ & $96.75 \pm 0.13$ \\
\hline ZT6 & $52 \pm 0.45$ & $7-8$ & $0.152 \pm 0.35$ & $2.63 \pm 0.16$ & $98.54 \pm 0.15$ & $98.39 \pm 0.73$ \\
\hline ZT8 & $50 \pm 0.92$ & $7-8$ & $0.114 \pm 0.13$ & $2.61 \pm 0.35$ & $98.75 \pm 0.91$ & $98.97 \pm 0.79$ \\
\hline ZT9 & $51 \pm 0.76$ & $7-8$ & $0.1 \pm 0.24$ & $2.63 \pm 0.24$ & $98.67 \pm 0.32$ & $98.79 \pm 0.12$ \\
\hline ZT10 & $51 \pm 0.42$ & $7-8$ & $0.15 \pm 0.16$ & $2.62 \pm 0.36$ & $98.43 \pm 0.07$ & $97.19 \pm 0.97$ \\
\hline ZT11 & $52 \pm 0.19$ & $7-8$ & $0.102 \pm 0.26$ & $2.65 \pm 0.52$ & $97.56 \pm 0.008$ & $98.64 \pm 0.04$ \\
\hline ZT12 & $51 \pm 0.35$ & $7-8$ & $0.101 \pm 0.12$ & $2.61 \pm 0.11$ & $99.18 \pm 0.28$ & $97.94 \pm 0.76$ \\
\hline ZT13 & $75 \pm 0.64$ & $7-8$ & $0.17 \pm 0.45$ & $2.78 \pm 0.3$ & $98.16 \pm 0.86$ & $97.94 \pm 0.37$ \\
\hline ZT14 & $76 \pm 0.53$ & $7-8$ & $0.125 \pm 0.21$ & $2.79 \pm 0.52$ & $98.54 \pm 0.65$ & $97.37 \pm 0.46$ \\
\hline ZT15 & $75 \pm 0.72$ & $7-8$ & $0.13 \pm 0.14$ & $2.77 \pm 0.42$ & $99.63 \pm 0.001$ & $97.64 \pm 0.43$ \\
\hline ZT17 & $75 \pm 0.92$ & $7-8$ & $0.1 \pm 0.12$ & $2.78 \pm 0.12$ & $98.07 \pm 0.02$ & $97.78 \pm 0.76$ \\
\hline ZT18 & $76 \pm 0.68$ & $7-8$ & $0.105 \pm 0.13$ & $2.76 \pm 0.32$ & $98.43 \pm 0.007$ & $98.49 \pm 0.07$ \\
\hline ZT19 & $75 \pm 0.37$ & $7-8$ & $0.1 \pm 0.24$ & $2.79 \pm 0.11$ & $97.71 \pm 0.008$ & $97.34 \pm 0.43$ \\
\hline ZT20 & $100 \pm 0.52$ & $7-8$ & $0.101 \pm 0.15$ & $2.88 \pm 0.23$ & $99.08 \pm 0.58$ & $98.49 \pm 0.48$ \\
\hline ZT21 & $101 \pm 0.82$ & $7-8$ & $0.127 \pm 0.24$ & $2.89 \pm 0.21$ & $98.1 \pm 0.41$ & $97.61 \pm 0.61$ \\
\hline ZT22 & $102 \pm 0.46$ & $7-8$ & $0.152 \pm 0.81$ & $2.89 \pm 0.24$ & $97.54 \pm 0.15$ & $98.64 \pm 0.51$ \\
\hline ZT23 & $51 \pm 0.53$ & $7-8$ & $0.105 \pm 0.64$ & $2.61 \pm 0.35$ & $98.13 \pm 0.001$ & $98.73 \pm 0.11$ \\
\hline ZT24 & $75 \pm 0.46$ & $7-8$ & $0.11 \pm 0.24$ & $2.76 \pm 0.11$ & $98.65 \pm 0.56$ & $98.84 \pm 0.26$ \\
\hline ZT25 & $101 \pm 0.56$ & $7-8$ & $0.121 \pm 0.35$ & $2.89 \pm 0.21$ & $99.75 \pm 0.12$ & $97.35 \pm 0.34$ \\
\hline STILNOCT & $101 \pm 0.18$ & $7-8$ & $0.101 \pm 0.26$ & $2.13 \pm 0.23$ & $99.43 \pm 0.68$ & $98.56 \pm 0.81$ \\
\hline ZT25 & $101 \pm 0.56$ & $7-8$ & $0.121 \pm 0.35$ & $2.89 \pm 0.21$ & $99.75 \pm 0.12$ & $97.35 \pm 0.34$ \\
\hline STILNOCT & $101 \pm 0.18$ & $7-8$ & $0.101 \pm 0.26$ & $2.13 \pm 0.23$ & $99.43 \pm 0.68$ & $98.56 \pm 0.81$ \\
\hline
\end{tabular}

Values are expressed as mean \pm SD for $a: n=20, b$ and $d: n=5$, c, e and $f: n=10$. SD: standard deviation

Table 8: Model dependent kinetic study for all formulation

\begin{tabular}{|c|c|c|c|c|c|}
\hline \multirow[t]{2}{*}{ Formulations } & \multirow{2}{*}{$\frac{\text { Zero-order }}{\mathrm{R} 2}$} & \multirow{2}{*}{$\frac{\text { First-order }}{\mathrm{R} 2}$} & \multirow{2}{*}{$\frac{\text { Higuchi }}{\text { R2 }}$} & \multicolumn{2}{|c|}{ Peppas } \\
\hline & & & & $\mathbf{R 2}$ & $\mathbf{n}$ \\
\hline ZT1 & 0.773 & 0.908 & 0.948 & 0.976 & 0.315 \\
\hline ZT2 & 0.791 & 0.881 & 0.959 & 0.967 & 0.369 \\
\hline ZT3 & 0.752 & 0.829 & 0.939 & 0.951 & 0.349 \\
\hline ZT4 & 0.772 & 0.837 & 0.947 & 0.945 & 0.379 \\
\hline ZT5 & 0.787 & 0.841 & 0.951 & 0.934 & 0.409 \\
\hline ZT6 & 0.745 & 0.787 & 0.931 & 0.925 & 0.373 \\
\hline ZT7 & 0.737 & 0.968 & 0.939 & 0.904 & 0.342 \\
\hline ZT8 & 0.793 & 0.952 & 0.956 & 0.974 & 0.329 \\
\hline ZT9 & 0.893 & 0.967 & 0.991 & 0.992 & 0.418 \\
\hline ZT10 & 0.843 & 0.968 & 0.979 & 0.989 & 0.801 \\
\hline ZT11 & 0.808 & 0.965 & 0.964 & 0.992 & 0.807 \\
\hline ZT12 & 0.766 & 0.933 & 0.94 & 0.988 & 0.819 \\
\hline ZT13 & 0.829 & 0.824 & 0.973 & 0.981 & 0.764 \\
\hline ZT14 & 0.815 & 0.908 & 0.972 & 0.994 & 0.919 \\
\hline ZT15 & 0.799 & 0.904 & 0.97 & 0.996 & 0.889 \\
\hline ZT16 & 0.973 & 0.99 & 0.974 & 0.986 & 0.767 \\
\hline ZT17 & 0.915 & 0.979 & 0.996 & 0.993 & 0.456 \\
\hline ZT18 & 0.941 & 0.919 & 0.993 & 0.988 & 0.494 \\
\hline ZT19 & 0.905 & 0.85 & 0.99 & 0.976 & 0.418 \\
\hline ZT20 & 0.982 & 0.981 & 0.968 & 0.989 & 0.801 \\
\hline ZT21 & 0.982 & 0.945 & 0.968 & 0.992 & 0.807 \\
\hline ZT22 & 0.981 & 0.8 & 0.967 & 0.988 & 0.819 \\
\hline ZT23 & 0.976 & 0.972 & 0.968 & 0.981 & 0.764 \\
\hline ZT24 & 0.994 & 0.932 & 0.943 & 0.994 & 0.919 \\
\hline ZT25 & 0.994 & 0.825 & 0.946 & 0.996 & 0.889 \\
\hline
\end{tabular}

tablets within a batch. Determine the amount of drug in each of 10 tablets using the analytical method as mentioned above.

\section{In vitro dissolution studies}

The in vitro drug release of zolpidem tartrate sustained-release tablets was determined using USP Dissolution Apparatus I (basket type)
(Electrolab TDT-08L). For first $2 \mathrm{~h}, 900 \mathrm{ml}$ of $0.01 \mathrm{~N} \mathrm{HCl}$ was used later for next $10 \mathrm{~h}, 7.4 \mathrm{pH}$ buffer at a speed of $50 \mathrm{rpm}, 5 \mathrm{ml}$ aliquot withdrawn for every hour up to $12 \mathrm{~h}$. Samples collected were analyzed by UV spectrophotometer (ELICO-164 double beam spectrophotometer) at a wavelength of $294.4 \mathrm{~nm}$ and $241.8 \mathrm{~nm}$.

\section{Drug-excipient compatibility studies}

Fourier transform infrared (FTIR) spectroscopy analysis

The spectrum analysis of pure drug and physical mixture of drug and different excipients which are used for the preparation of tablets was studied by FTIR. FTIR spectra were recorded by preparing potassium bromide $(\mathrm{KBr})$ disks using a Shimadzu Corporation (Kyoto, Japan) facility (model - 8400S). Potassium bromide (KBr) disks were prepared by mixing few mg of sample with potassium bromide by compacting in a hydrostatic press under vacuum at 6-8 tons pressure. The resultant disc was mounted in a suitable holder in IR spectrophotometer, and the IR spectrum was recorded from $4000 / \mathrm{cm}$ to $500 / \mathrm{cm}$ in a scan time of $12 \mathrm{~min}$. The resultant spectrum was compared for any spectral changes. They were observed for the presence of characteristic peaks for the respective functional group in the compound.

\section{Powder X-Ray diffraction (XRD) analysis}

The crystallinity of the drug, polymer and optimized mixtures were studied by powder XRD. The powder XRD analysis was performed using Shimadzu XRD-7000, XRD using Copper K $\alpha\left(\lambda=1.5406 \mathrm{~A}^{\circ}\right)$ radiation. The data were recorded over a scanning $2 \theta$ range of $5^{\circ}-50^{\circ}$ at a step time of 0.045 steps $/ 0.5 \mathrm{~s}$.

\section{Differential scanning calorimetry}

The physical nature of the drug, polymer and optimized formulations were studied by differential scanning calorimeter (DSC). DSC analysis was performed using Shimadzu DSC-60 DSC. The instrument was calibrated with indium standard. 3-5 mg samples were weighed and placed in a closed, hermetic sample pans with pinhole. Thermograms were obtained by heating the sample at a constant rate $10^{\circ} \mathrm{C} / \mathrm{min}$. 
A dry purge of nitrogen gas $(50 \mathrm{ml} / \mathrm{min})$ was used for all runs. Samples were heated from $0^{\circ} \mathrm{C}$ to $350.0^{\circ} \mathrm{C}$. The melting point, heat of fusion, disappearance of the crystalline sharp peak of the drug and appearance of any new peak and peak shape were noted [13].

\section{Model dependent methods}

Regression coefficients $\left(\mathrm{r}^{2}\right)$ were calculated for all the formulations. Release component " $\mathrm{n}$ " was calculated from KorsmeyerPeppas equation. Based on $\mathrm{n}$ value the release mechanism was characterized $[14,15]$

\section{Comparison of prepared optimized formulation with marketed} formulation

The in vitro dissolution release of the optimized formulations was compared with the marketed STILNOCT $12.5 \mathrm{mg}$ tablets. The STILNOCT $12.5 \mathrm{mg}$ tablets were packed and marketed by Sanofi-Synthelabo Ltd, Mumbai, India. As the $6.25 \mathrm{mg}$ twice a day tablets are not available in the market the comparison with optimized formulation was done by $12.5 \mathrm{mg}$ per day tablet.

Performing accelerated stability studies for the optimized formulations

The optimized formulation was subjected to stability studies at $40{ }^{\circ} \mathrm{C} \pm 2{ }^{\circ} \mathrm{C} / 75 \% \pm 2 \% \mathrm{RH}$ (zone III) for a period of 3 months. Each tablet was individually wrapped in aluminum foil and packed in amber colored bottle and put at the above-specified condition in a heating humidity chamber for 3 months. For every month tablets were analyzed for the physicochemical evaluation and in vitro drug release studies.

\section{RESULTS AND DISCUSSION}

\section{Preformulation studies}

Values for the angle of repose were found in the range of $25.78 \pm 0.82$ $27.89 \pm 0.92$ (I.P limits $25-30$ ) showing that the blend of powder was free-flowing. The value for Carr's index was in between 11.19 \pm 0.339 and $14.53 \pm 0.926$ (I.P limits 11-15) indicating that all batches of powder blends were having good compressibility. Hausner's ratio was to be within the limits $1.126 \pm 0.011-1.150 \pm 0.001$ (I.P limits $1.12-1.18$ ). The results showed that all the formulations showed good blend properties.

\section{Evaluation of prepared tablets}

Evaluation of prepared matrix tablets were conducted, and the values for wt variation are in the range of $49 \pm 0.12-51 \pm 0.82,74 \pm 0.45$ $76 \pm 0.68,100 \pm 0.52-102 \pm 0.46$ (limits $10 \%$ deviation), hardness $7-8$ (I.P limits 4-8), friability $0.1 \pm 0.24-0.17 \pm 0.45$ (limits $0.5-1 \%$ ), thickness $2.60 \pm 0.24-2.89 \pm 0.24$ (limits $\pm 5 \%$ deviation), drug content $97.54 \pm 0.15-$ $99.75 \pm 0.12$, and content uniformity $97.34 \pm 0.43-98.97 \pm 0.79$ (limits $85-115 \%)$. This indicates that the evaluation parameters for all the formulations are within the limits Table 7 .

\section{Appearance of tablets}

To discriminate the control release upper and lower layers, they are colored with Erythrosine B is shown in Plate 1. The swelling of the top and bottom layers of the triple-layered tablets during the dissolution is shown in Plate 2.

\section{In vitro dissolution studies}

Sustained release matrix tablet was formulated using Lubritab as a hydrophobic polymer, AVICEL PH 102 as diluent, magnesium stearate and talc as lubricant and glidant. Initially, the formulations were prepared by MG and DC techniques. But from the results, it was observed that the formulation prepared by DC could not sustain the drug release on account of its eroding nature. Hence, MG was followed for the preparation of polymer granules, and this step improved the flow properties suitable for compression of the tablets as shown in (Fig. 1). As zolpidem tartrate has absorption throughout the GIT, the dissolution was performed in 7.4 and $6.8 \mathrm{pH}$ for optimizing media. From the dissolution results, it was observed that there was no significant difference in the drug release from both media, so further work is continued with the $7.4 \mathrm{pH}$ media which covers most of the intestinal part (Fig. 2).

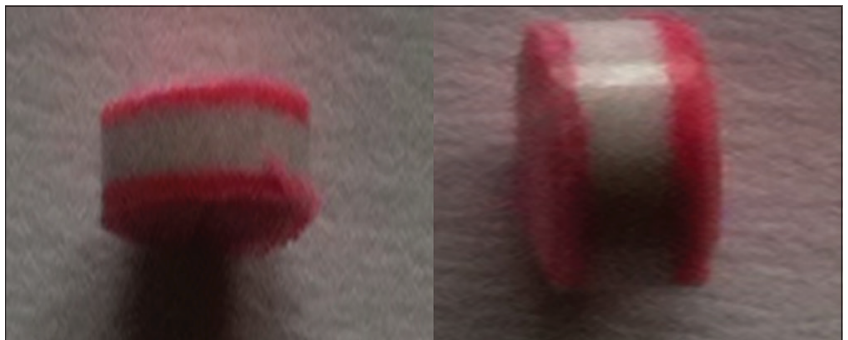

Plate 1: Vertical view of tri-layered tablets containing hydrophobic matrix core layered with hydrophilic polymer

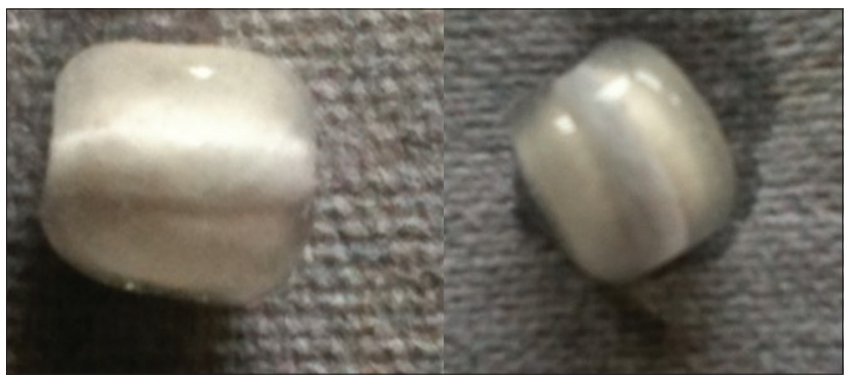

Plate 2: Swelling of top and bottom HPMC K4M layers

The effect of polymer in different ratios was investigated for optimizing the complete drug release in $12 \mathrm{~h}$. The results showed that the formulation ZT1 exhibited initial burst release of drug and the drug release was $98.3 \%$ at $12^{\text {th }} \mathrm{h}$ whereas in the remaining formulations there is no initial burst release, but further retardation of drug release was observed. ZT2 showed $29.3 \%$ drug release in $2^{\text {nd }} \mathrm{h}$ which is within the limits but could release only $56.1 \%$ at $12^{\text {th }} \mathrm{h}$. Hence, there is a chance for optimizing ZT1 for further study as shown in (Fig. 3). As ZT1 exhibited initial burst release, it was layered with different concentrations of HPMC K4M to control the initial release. However, further retardation of drug release was observed so to enhance the drug release channeling agents can be included in it, but the problem with this is the initial drug release also increases. As the capacity of $6 \mathrm{~mm}$ punch is up to $100 \mathrm{mg}$ which is not suitable if the concentration of HPMC K4M is increased in formulations ZT8 and ZT9 to reduce the initial drug release. Hence, the formulation ZT1 was not optimized, and the further study was continued with ZT2 (Fig. 4).

The optimized formula contained the polymer (Lubritab) of 25\%, diluent (AVICEL PH 102) of 50\%, and glidant of $0.3 \%$. The drug release was slow and extended over time depending on the concentration of polymer. Hence, along with polymer, different concentrations of HPMC K100 and lactose monohydrate as channeling agents were added for complete release of drug within $12 \mathrm{~h}$. These formulations failed to produce the required initial release of $20 \%$ (Fig. 5).

Then three-layered tablets as shown in Plates 1 and 2 were prepared where the top and bottom layers are of highly viscous polymer HPMC $4 \mathrm{KM}$ at concentrations $33.3 \%$ and $50 \%$ to control the initial burst release. Moreover, the complete release of drug within $12 \mathrm{~h}$ was obtained by changing concentration of channeling agents (Fig. 6). Formulations ZT22 containing $22.5 \%$ of channeling agent layered with 33.3\% HPMC K4M and ZT25 containing $12.5 \%$ of lactose monohydrate as channeling agent layered with 50\% HPMC K4M showed effective control of initial release and attained $98 \%$ of drug release in $12 \mathrm{~h}$ were finally optimized (Fig. 7).

\section{Powder XRD analysis}

The powder XRD pattern of pure drug exhibited sharp, highly intense peaks indicating the crystalline nature of drug at $2 \theta$ diffraction angels of $17.2^{\circ}, 19.4^{\circ}, 21.3^{\circ}, 23.4^{\circ}, 30.6^{\circ}, 44.1^{\circ}, 65.3^{\circ}$, and $88.5^{\circ}$ as shown in Fig. 9a. The peaks remained unaltered in the ZT22, but their relative intensity was decreased due to change in resolution of Y-axis as 


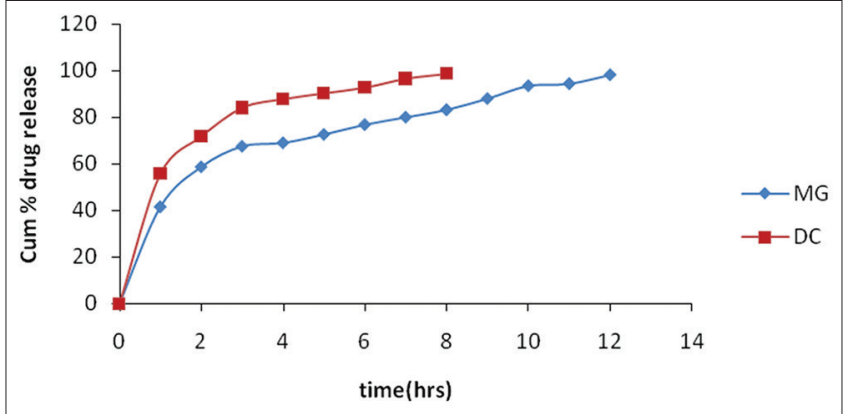

Fig. 1: Dissolution profile of formulation for optimization of tableting method

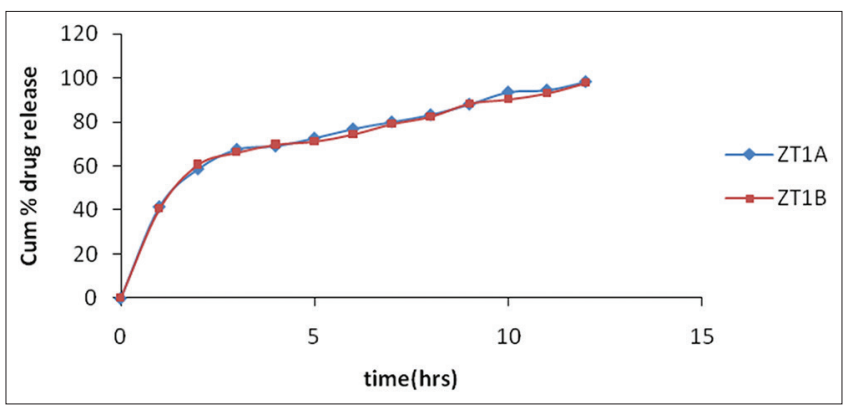

Fig. 2: Dissolution profile of ZT1A and ZT1B for media optimization

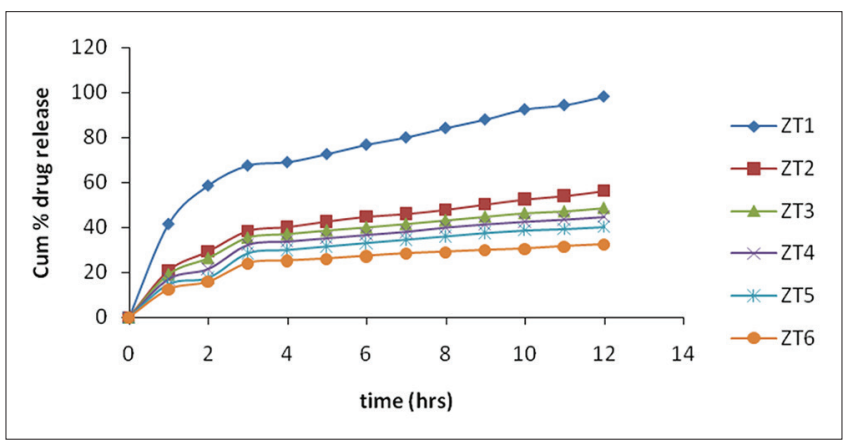

Fig. 3: Dissolution profiles of formulations with different concentrations of polymer

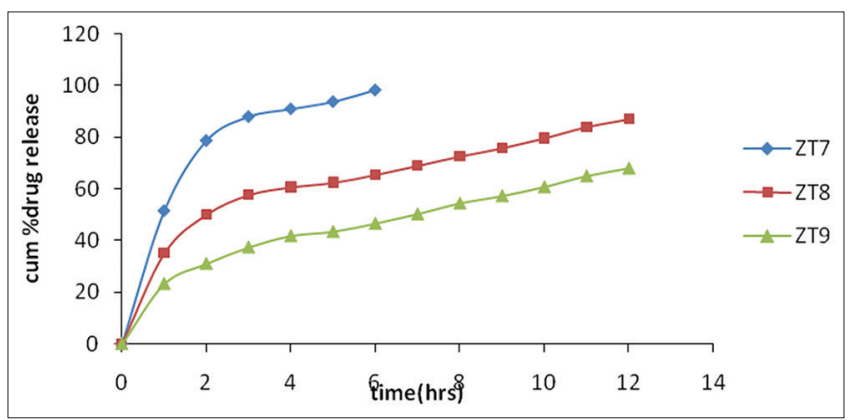

Fig. 4: Dissolution profiles of formulations for optimization of polymer concentration

shown in Fig. $9 \mathrm{c}$ and the results are found to be similar to the previous literature report.

\section{Differential scanning calorimetry}

The principal peaks of zolpidem tartrate were observed at 1635.52 , $1508.23,1404.08$, and $1342.36 / \mathrm{cm}$ indicating the presence of $\mathrm{C}=\mathrm{O}, \mathrm{N}-\mathrm{H}$,

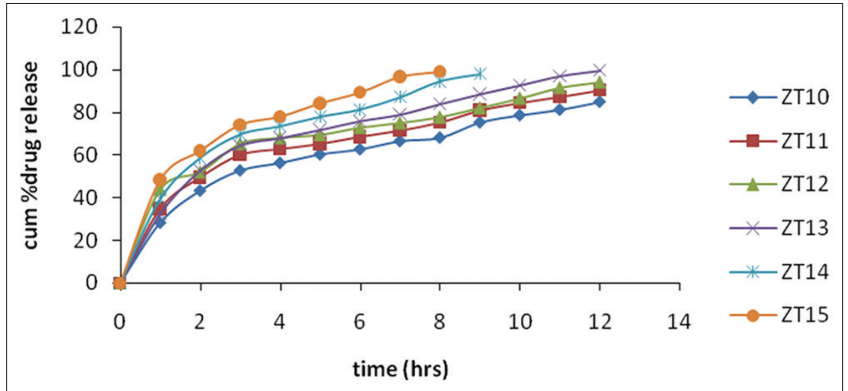

Fig. 5: Dissolution profiles of formulations with channeling agents

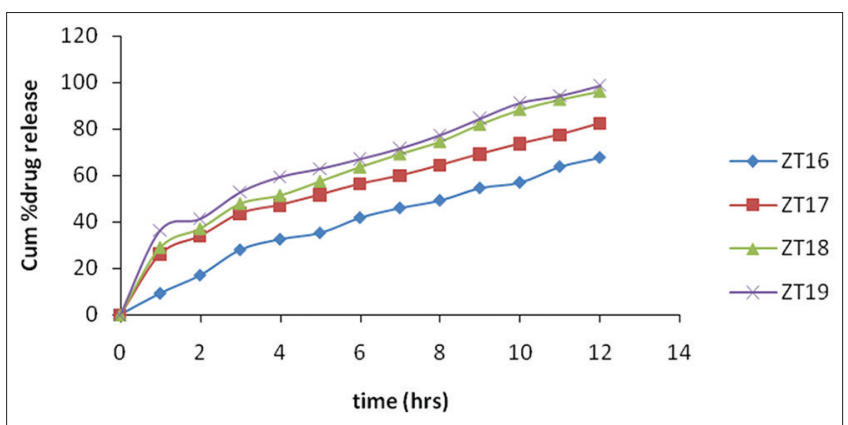

Fig. 6: Dissolution profiles of formulations layered with HPMC K4M

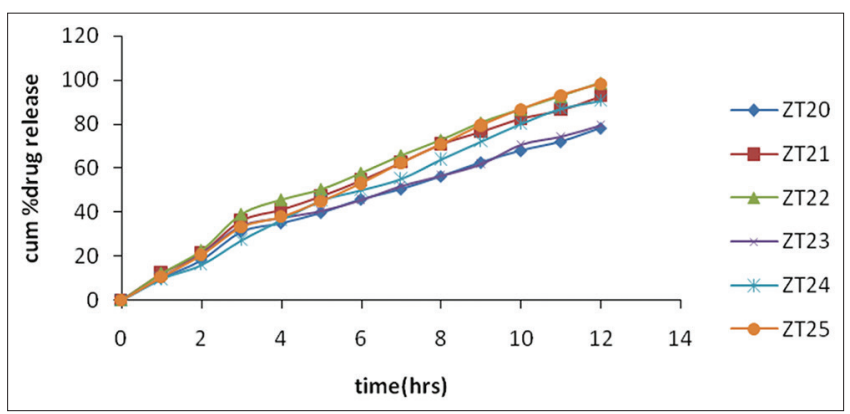

Fig. 7: Dissolution profiles of formulations for optimization of channeling agents in layered tablets

$\mathrm{CH}_{3}$, and C-N groups as shown in Fig. 8a. It was observed that there was no change in the characteristic peaks of the drug in the FTIR spectra of ZT22 as shown in Fig. 8c suggesting that there were no physical or chemical interactions and there is no functional alteration of the drug as reported in previous literature [6].

\section{Drug-excipients compatibility studies}

FTIR spectroscopy analysis

DSC of the drug showed a sharp characteristic endothermic peak at $193.48^{\circ} \mathrm{C}$ corresponding to the melting point of zolpidem tartrate; thus, it signifies the presence of a pure form of zolpidem tartrate as shown in Fig. 10a. The thermogram of Lubritab showed a sharp endothermic peak at $63.39^{\circ} \mathrm{Ccorresponding} \mathrm{to} \mathrm{the} \mathrm{melting} \mathrm{point} \mathrm{of} \mathrm{Lubritab} \mathrm{as}$ shown in Fig. 10b. The thermogram of the drug in ZT22 does not show a profound shift in peaks as shown in Fig. 10c indicating compatibility which is similar to previous literature report.

The drug excipient compatibility studies revealed from FTIR, PXRD, and DSC infers that there is no change in the characteristics of the drug during the formulation development and compression. 


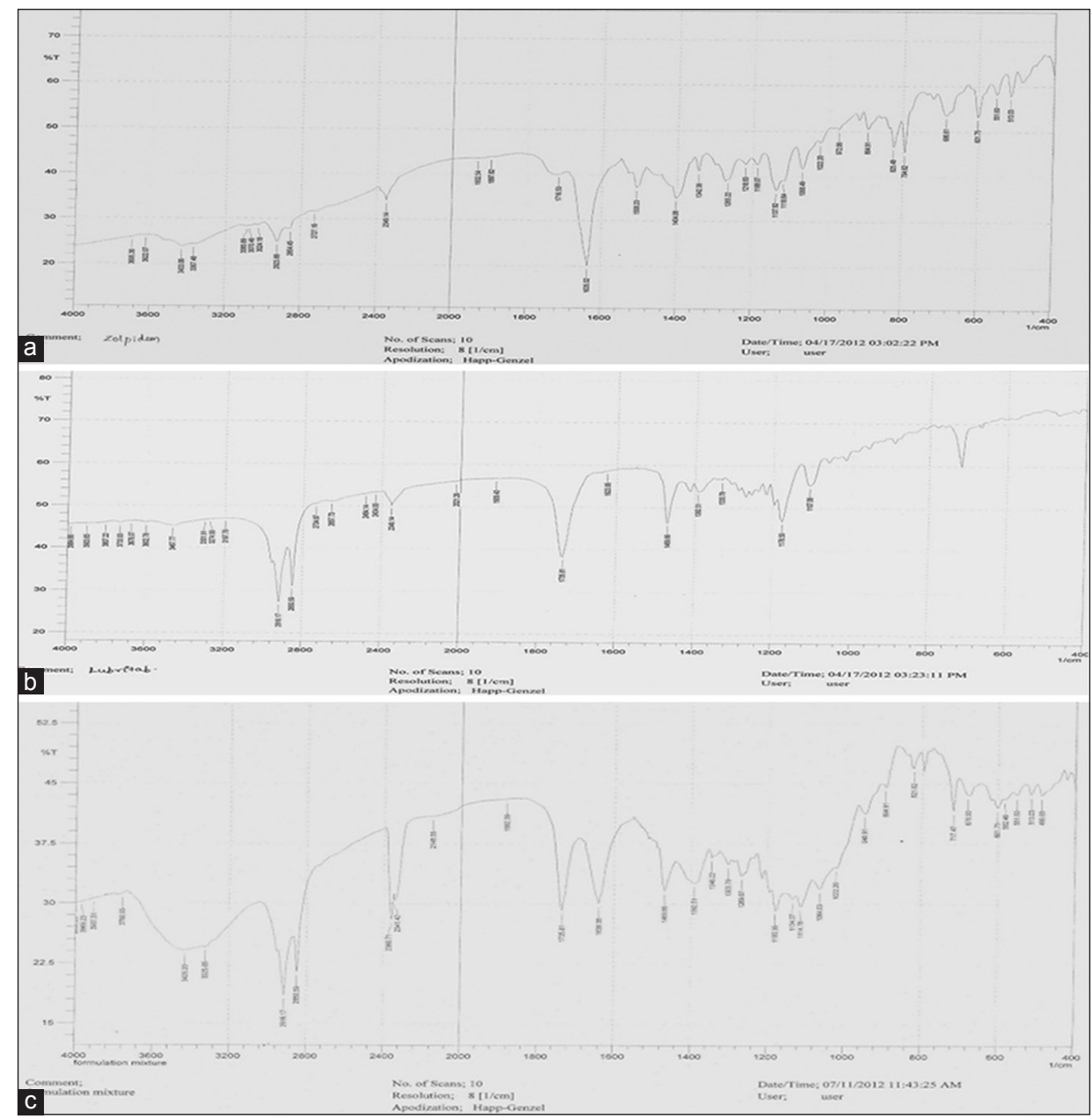

Fig. 8: Fourier transformer infrared spectra of (a) zolpidem tartrate (b) Lubritab (c) ZT22

Table 9: Physicochemical properties of ZT22 during accelerated stability studies

\begin{tabular}{|c|c|c|c|c|}
\hline \multirow[t]{2}{*}{ Parameters } & \multicolumn{4}{|l|}{ Time in months } \\
\hline & 0 (initial) & $1^{\text {st }}$ month & $2^{\text {nd }}$ month & $3^{\text {rd }}$ month \\
\hline Appearance & White to off-white & White to off-white & White to off-white & White to off-white \\
\hline Hardness $\left(\mathrm{kg} / \mathrm{cm}^{2}\right)$ & $7.6 \pm 0.32$ & $7.4 \pm 0.13$ & $7.2 \pm 0.51$ & $7.1 \pm 0.65$ \\
\hline Drug content (\%) & $97.71 \pm 0.008$ & $97.11 \pm 0.001$ & $96.24 \pm 0.068$ & $96.10 \pm 0.001$ \\
\hline
\end{tabular}

Values are expressed as mean \pm SD, $n=3$. SD: Standard deviation

Table 10: Physicochemical properties ofZT25 during accelerated stability studies

\begin{tabular}{|c|c|c|c|c|}
\hline \multirow[t]{2}{*}{ Parameters } & \multicolumn{4}{|l|}{ Time in months } \\
\hline & 0 (Initial) & $1^{\text {st }}$ month & $2^{\text {nd }}$ month & $3^{\text {rd }}$ month \\
\hline Appearance & White to off-white & White to off-white & White to off-white & White to off-white \\
\hline Hardness $\left(\mathrm{kg} / \mathrm{cm}^{2}\right)$ & $7.6 \pm 0.22$ & $7.54 \pm 0.52$ & $7.42 \pm 0.43$ & $7.3 \pm 0.12$ \\
\hline Drug content (\%) & $97.54 \pm 15$ & $96.12 \pm 0.55$ & $95.91 \pm 0.26$ & $95.82 \pm 0.53$ \\
\hline
\end{tabular}

Values are expressed as mean \pm SD, $n=3$. SD: Standard deviation

\section{Model dependent methods}

Release kinetics for all the formulations were calculated using Microsoft Office Excel 2007 version. The release data were analyzed by fitting the drug release profiles of all the formulations into zeroorder release model, first-order release model, Higuchi model, and Korsmeyer-Peppas model. Regression coefficients $\left(\mathrm{r}^{2}\right)$ were calculated for all the formulations. The apparent dissolution rate constant or zeroorder release constant $\mathrm{K}_{0}$ was calculated for zero-order release model, first-order release constant $\mathrm{K}_{1}$ was calculated for first-order release model, Higuchi dissolution constant $\mathrm{K}_{\mathrm{H}}$ was calculated for Higuchi model, and release exponent $\mathrm{n}$ was calculated for Korsmeyer-Peppas model.

Regression coefficients were reported for all the formulations. ZT22 and ZT25 were considered as optimized formulations on account of their reproducible and promising drug release modulation. The optimized formulations by kinetics (based on the highest $r^{2}$ values) followed zero order. The release component " $\mathrm{n}$ " was calculated from the Korsmeyer- 


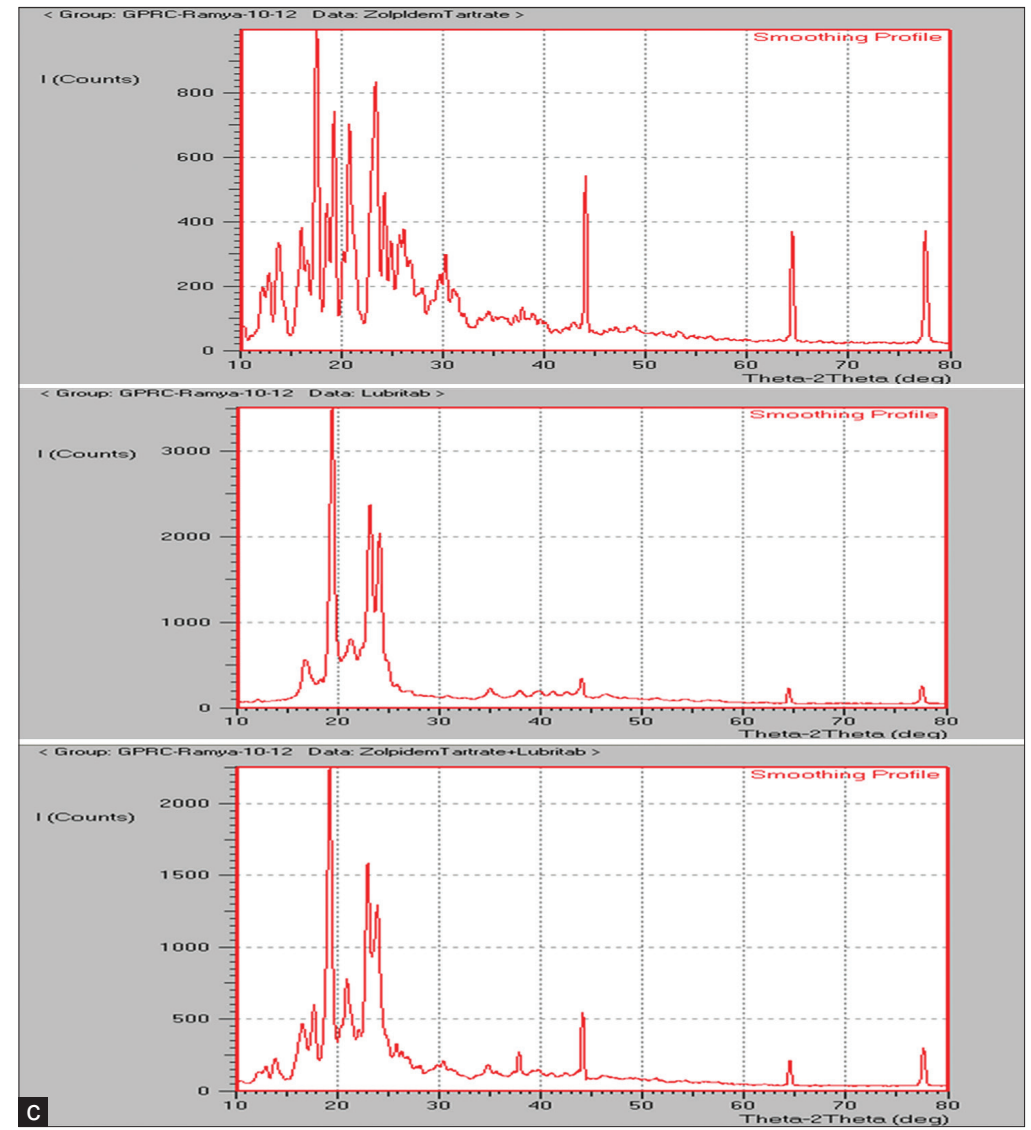

Fig. 9: P-XRD spectra of (a) zolpidem tartrate (b) Lubritab (c) ZT22

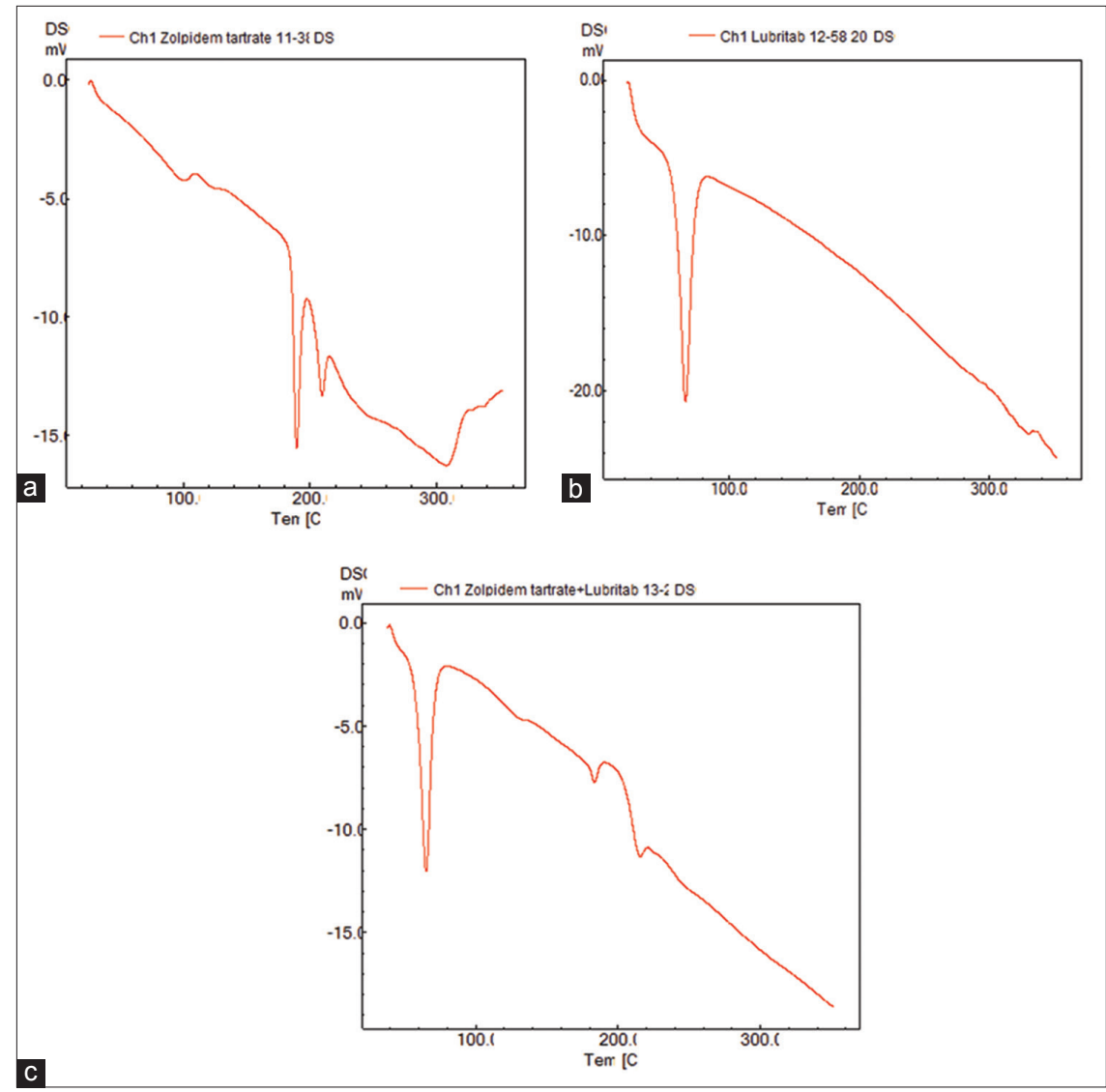

Fig. 10: DSC thermograms of (a) zolpidem tartrate (b) Lubritab (c) ZT22 


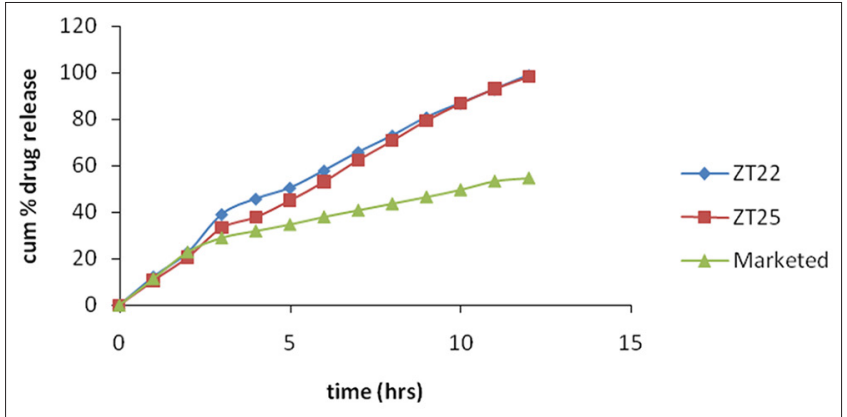

Fig. 11: Comparison of in vitro drug release of optimized formulations with marketed formulation

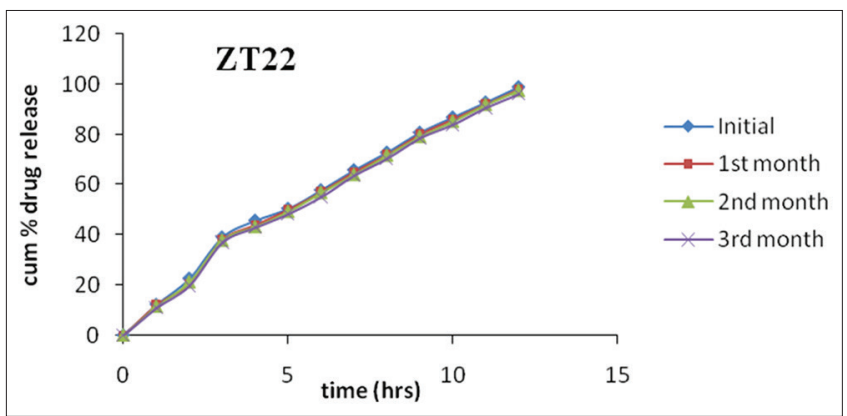

Fig. 12: Dissolution profile of optimized formulation ZT22

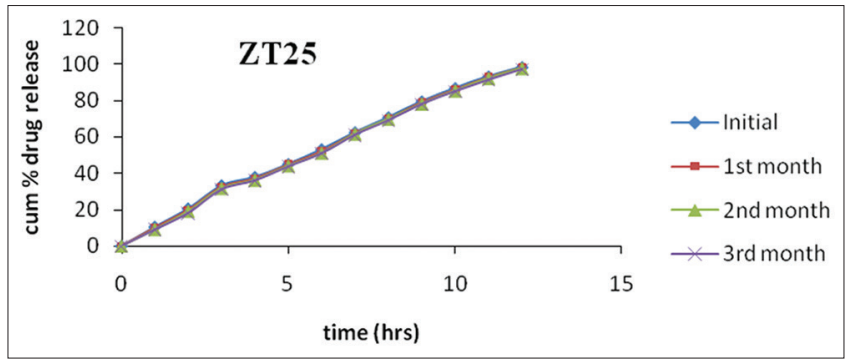

Fig. 13: Dissolution profile of optimized formulation ZT25

Peppas kinetics equation which revealed that the formulations followed anomalous transport mechanism in drug release Table 8.

Comparison of in vitro drug release of optimized formulations with marketed formulation

The in vitro drug release of the marketed formulation at $12^{\text {th }} \mathrm{h}$ was found to be $6.25 \mathrm{mg}$ which is similar to the optimized formulations at the same time point (Fig. 11).

The optimized formulations were compared with the marketed formulation (STILNOCT $12.5 \mathrm{mg}$ ). As the $6.25 \mathrm{mg}$ twice a day tablets are not available the comparison is done using $12.5 \mathrm{mg}$ per day tablet. The in vitro drug release of the marketed formulation at $12^{\text {th }} \mathrm{h}$ was found to be $6.25 \mathrm{mg}$ which is similar to the optimized formulations at the same time point.
Performing accelerated stability studies for the optimized formulations

The stability of promising zolpidem tartrate matrix tablets ZT22 and ZT25 were determined by performing stability studies for 3 months at accelerated conditions of $40 \pm 2^{\circ} \mathrm{C} / 75 \pm 2 \% \mathrm{RH}$. The optimized formulations were found to be stable, with insignificant change in the appearance, hardness, drug content, and in vitro drug release as given in Tables 9 and 10 as well as shown in Figs. 12 and 13 .

\section{CONCLUSIONS}

Insomnia is characterized by difficulties with sleep onset and or sleep maintenance can be treated successfully using the optimized formulations ZT22 and ZT25 for prompt onset of action of drug over a prolonged period of time which may lead to improved efficacy, better patient compliance, reduction of frequency of administration, and avoidance of fluctuations associated with the conventional immediate release formulations.

\section{REFERENCES}

1. Swarbrick J. Encyclopedia of Pharmaceutical Technology. $3^{\text {rd }}$ ed., Vol. I. New York: Informa Healthcare; 2006. p. 1242.

2. Hoffman A. Pharmacodynamic aspects of sustained release preparations. Adv Drug Deliv Rev 1998:33:185-99.

3. Yie WC. Text Book of Novel Drug Delivery System. $2^{\text {nd }}$ ed. New York: Marcel Dekker Inc.; 1992. p. 2.

4. Siahi MR, Barzegar-Jalali M, Monajjemzadeh F, Ghaffari F, Azarmi S. Design and evaluation of 1-and 3-layer matrices of verapamil hydrochloride for sustaining its release. AAPS PharmSciTech 2005;6:E626-32.

5. Maejima T, Osawa T, Nakajima K, Kobayashi M. Application of tumbling melt granulation (TMG) method for preparing controlled release beads coated with hydrogenated castor oil. Chem Pharm Bull 1997; 45:904-10

6. Prajapati ST, Patel AN. Formulation and evaluation of controlledrelease tablet of zolpidem tartrate by melt granulation technique. ISRN Pharm 2011;2011:1-8.

7. Ochoa L, Igartua M, Hernández RM, Gascón AR, Pedraz JL. Preparation of sustained release hydrophilic matrices by melt granulation in a highshear mixer. J Pharm Pharm Sci 2005;8:132-40.

8. Kulkarni SV, Patel N. Formulation and in vitro evaluation of sustained release matrix tablet of zolpidem tartrate. Int J Pharm Tech Res 2011;3:858-63.

9. Gohel MC, Bariya SH. Fabrication of triple-layer matrix tablets of venlafaxine hydrochloride using xanthan gum. AAPS PharmSciTech 2009; 10:624-30.

10. Park JS, Shim JY, Park JS, Choi YW, Jeong SH. A novel three-layered tablet for extended release with various layer formulations and in vitro release profiles. Drug Dev Ind Pharm 2011;37:664-72.

11. Potturi PK, Sudhakar Y. Development and in vivo evaluation of tolcapone controlled release trilayer matrix tablets by geomatrix technology. Int J Pharm Pharm Sci 2016;8:318-24.

12. Leon L, Liberman HA, Kanig JL. The Theory and Practice of Industrial Pharmacy. $3^{\text {rd }}$ ed. Bombay: Varghese Publishing House; 1991. p. $171-95$

13. Panda N, Reddy AR, Reddy GV, Sultana A. Formulation design and in vitro evaluation of bilayer sustained release matrix tablets of doxofylline. Int J Pharm Pharm Sci 2015;7:74-83

14. Yuksel N, Kanik AE, Baykara T. Comparison of in vitro dissolution profiles by ANOVA-based, model-dependent and independent methods. Int J Pharm 2000;209:57-67.

15. Costa P, Jose MS. Modeling and comparison of dissolution profiles. Eur J Pharm Sci 2001;13:123-33. 